\title{
Incorporación de la Etnomatemática de los Kañaris de Lambayeque en la práctica docente intercultural bilingüe
}

\author{
Jesús Eloy Reyes Huamán \\ Investigador independiente y promotor de la cultura \\ y la lengua originaria de la nación Kañari - Perú \\ jesus.eloy.rey@hotmail.com.
}

Recibido: 9 -febrero-2018 / Aceptado: 31 - julio - 2018

\section{Resumen}

Este trabajo describe el rescate de los conocimientos ancestrales de un pueblo originariollamado Kañari recuperados mediantela etnografía, ysuincorporación en la práctica pedagógica del docente de Educación Intercultural Bilingüe, con el propósito de que los estudiantes logren aprendizajes y se fortalezca la cultura milenaria y la lengua originaria. La investigación etnográfica, el diseño y aplicación de la propuesta pedagógica se realizó en la Institución Educativa N. 10244, una escuela rural de Educación Básica del nivel primario, del caserío Huamachuco, Distrito Kañaris, Región Lambayeque, en Perú. Esta oportunidad compartiremos la investigación, el rescate y la incorporación de algunos conocimientos, valores, tecnologías y ciencias propias de los Kañaris tales como: (1) La mitología ancestral que da cuenta de dioses y seres mitológicos de la religión y cosmovisión propia de este grupo étnico cultural; (2) El sistema de caminos ancestrales que formaba parte del "Qapaq Nan" del Tawantinsuyo y las pervivencias culturales milenarias que aún se mantienen vivas; y (3) El estudio de la etnomatemáticas: el empleo de algunas unidades de medidas e instrumentos ancestrales de cálculo aritmético y registro numérico entre ellas la "yupana inka" y el "khipu”. Así mismo se propone una secuencia metodológica para el abordaje y el tratamiento curricular de los conocimientos matemáticos de un pueblo originario. 
Palabras clave: Kañaris, pueblos originarios, conocimientos ancestrales, antropometría, etnomatemática.

\begin{abstract}
This work describes the rescue of the ancestral knowledge of an indigenous people called KANARIS recovered through ethnography, and its incorporation into the pedagogical practice of the Intercultural Bilingual Education teacher, with the purpose that the students achieve learning and the millenary culture is strengthened and the original language. The ethnographic research, the design and application of the pedagogical proposal was made in the Educational Institution N. 10244, a rural school of Basic Education of the primary level, of the Huamachuco farmhouse, Kañaris District, Lambayeque Region, in Peru. This opportunity we will share research, rescue and incorporation of some knowledge, values, technologies and sciences of the Kañaris such as: (1) The Ancestral Mythology that accounts for gods and mythological beings of the religion and worldview of this group cultural ethnicity; (2) The System of Ancestral Roads that was part of the "Qapaq Nan" of the Tawantinsuyo and the millenary cultural survivals that are still alive; and (3) The study of Ethnomathematics: the use of some units of measurements and ancestral instruments of arithmetic calculation and numerical registration, among them the "Yupana Inka" and the "Khipu". Likewise, a methodological sequence is proposed for the approach and curricular treatment of the mathematical knowledge of a native people.
\end{abstract}

Keywords: Kañaris, indigenous peoples, ancestral knowledge, anthropometry, ethnomathematics. 


\section{Introducción}

$\square 1$ acervo cultural de los pueblos originarios es un preciado tesoro que debe 4 preservarse e inculcarse a las nuevas generaciones, incorporarlo en el currículo escolar es una manera de hacerlo para fortalecer su identidad y evitar la pérdida de los saberes ancestrales de nuestros pueblos indígenas. El presente trabajo da cuenta de la investigación, el rescate y la incorporación de algunos conocimientos, valores, tecnologías y ciencias ancestrales propias de los Kañaris y hace una propuesta pedagógica para su incorporación en la Educación Intercultural Bilingüe.

Los saberes ancestrales de los Kañaris son poco conocidos y difundidos. Esto sumado a la desvalorización, la discriminación y el pensamiento colonizador que experimentamos han generado desinterés y desconocimiento en las nuevas generaciones, y corren el riesgo de ser totalmente olvidados. Debido a esta imperiosa necesidad se diseña e implementa el proyecto de construir prácticas pedagógicas significativas, de contexto y de alta demanda cognitiva, toda vez que en éstas se incorporan los saberes ancestrales como medio para lograr aprendizajes y a su vez se fortalezcan la lengua originaria y la cultura local.

Este texto se inicia con una breve descripción de los Kañaris de Lambayeque; se comparte la metodología de investigación y el proceso seguido para la incorporación de los conocimientos ancestrales en la práctica pedagógica docente; luego se detalla la recopilación etnográfica de algunas prácticas y saberes ancestrales de los Kañaris, entre ellos la etnomatemática; seguidamente se explicita una propuesta didáctica para el abordaje y tratamiento curricular de los conocimientos matemáticos de un pueblo originario. Finalmente se reflexiona sobre los logros de aprendizaje en los niños y niñas; y su aporte para la construcción de un etno-currículo y una propuesta pedagógica propia.

Puesto que, se trata de una experiencia de incorporación de los saberes de un pueblo originario quechua, en el documento se han empleado algunos términos quechuas y voces oriundas del lugar; pero esto no dificulta su comprensión.

\section{Los Kañaris de Lambayeque}

Con la denominación Kañaris, en los Andes, existen al menos dos grupos culturales diferenciados, uno en Ecuador y otro en Perú, por referencias etnohistóricas se sabe que la etnia ecuatoriana fue desplazada en calidad de "mitmas" por los incas, a varios lugares del territorio andino, para Pilar Remy el grupo peruano procede de Quito (Remy1986, citado por Fernández 2010).

Sin embargo, los Kañaris, somos un pueblo originario establecidos hace aproximadamente 5000 a 2500 años atrás en los bosques montanos húmedos y el páramo de la Cordillera de los Andes de la Región de Lambayeque. Con avanzada sabiduría y tecnología nuestros ancestros dominaron esta difícil topografía y triunfaron desde 
hace milenios. Somos herederos de un bastión cultural milenario: tenemos nuestro propio idioma, nuestro territorio, nuestras formas de vestir y nuestros símbolos andinos, nuestra propia "religión", cosmovisión y filosofía; narraciones ancestrales; rituales, cantos y danzas sagradas; restos arqueológicos, entre otras evidencias y manifestaciones culturales primigenias que dan cuenta de ello.

El territorio de los Kańaris, se ubica en la zona rural andina y es uno de los distritos más alejados de la región. Políticamente pertenece a la provincia de Ferreñafe de la región Lambayeque, con una población aproximada de 20 mil personas distribuidas entre los 1.000 y 4.000 msnm en ambas vertientes de la Cordillera Occidental de los Andes. La lengua originaria es el quechua, una variante que aún conserva algunas propiedades consonánticas y morfológicas del proto-quechua, clasificado por (Torero, 1964) en el grupo QII. ${ }^{1}$

\section{Metodología de investigación y proceso seguido para la incorporación de los co- nocimientos ancestrales en la práctica pedagógica docente}

La investigación etnográfica, el diseño y aplicación de la propuesta pedagógica se realizó en la Institución Educativa N. 10244, una escuela rural de Educación Básica del nivel primario, del caserío Huamachuco, Distrito Kañaris, Región Lambayeque, en Perú. La escuela cuenta con un solo docente que tiene a su cargo 31 estudiantes que cursan del 1 ro al 6to grado de estudios, y cuyas edades cronológicas oscilan entre los 6 y los 14 ańos de edad.

Este proyecto se viene desarrollando desde el año 2016, se han utilizado diversas fuentes etnohistóricas y se enmarca dentro del Programa de Etnomatemática ( D’Ambrosio, 2014), se eligió una metodología etnográfica (Martínez, 1998) por su orientación naturalista y fenomenológica: la constante atención al contexto sociocultural que caracteriza la componente "étnica" de la investigación.

Por lo general, la práctica docente ha contribuido a la pérdida de la lengua originaria y además de no lograr aprendizajes en los estudiantes, ha ignorado histórica y gravemente los saberes ancestrales de la comunidad. La cultura ancestral y la lengua originaria de los Kańaris agonizan y nuestros estudiantes tienen serias dificultades de aprendizaje. Por ello la imperiosa necesidad de implementar prácticas pedagógicas situadas, que incorporen las sabidurías ancestrales de nuestros pueblos originarios, logren aprendizajes y se fortalezca la cultura y la lengua originaria.

1 Los estudios dialectológicos seminales del lingüista Alfredo Torero (1964) clasificaron las variedades de la familia lingüística quechua en dos subfamilias o ramas. Una de estas ramas es el llamado quechua I. Esta rama comprende las variedades distribuidas en la Sierra central y norcentral del Perú, por ambas vertientes de la cordillera de los Andes, dentro de las jurisdicciones de los departamentos peruanos de Lima, Junín, Pasco, Huánuco y Ancash. La otra rama es la denominada quechua II. Se expande por el norte entre el suroeste de Colombia, Ecuador y el norte de Perú, mientras que por el sur se expande entre el Perú meridional, Bolivia y el noroeste argentino, con probables hablantes en la región próxima de Chile. 
Lamentablemente no hemos sido preparados para sumir este tipo de educación, siempre nos han dicho qué hacer, pero no nos han enseńado cómo hacerlo, y tampoco contamos con herramientas específicas que sirvan de referentes pedagógicos. Por tanto, la investigación, el rescate y la incorporación de los conocimientos ancestrales de un pueblo originario en la práctica pedagógica, no resultará una tarea nada sencilla.

Los procesos seguidos para incorporación de los conocimientos ancestrales de un pueblo originario en la práctica pedagógica, que se implementó son los siguientes:

a) La investigación etnográfica y profundización de los conocimientos ancestrales del pueblo originario.

b) La planificación de unidades didácticas y diseño de sesiones de aprendizaje incorporando los conocimientos ancestrales.

c) La validación y evaluación de la planificación curricular y la propuesta didáctica en aula; posteriormente la socialización y retroalimentación de la experiencia docente a nivel de red educativa.

La planificación curricular de unidades didácticas y sesiones de aprendizaje materializan la propuesta de incorporación de los saberes ancestrales de un pueblo originario en la práctica pedagógica docente. Sin embargo, estos procesos de planificación curricular demandan del docente de Educación Intercultural Bilingüe movilizar y combinar estratégicamente diversas competencias y dominios: el conocimiento de la cultura y la cosmovisión del pueblo indígena, el dominio de la lengua originaria, los procesos pedagógicos, didáctica y estrategias específicas. Dicho de otro modo: un dominio altamente cultural y una competencia pedagógica.

\section{Algunos conocimientos y prácticas ancestrales del pueblo Kañari}

\subsection{Mitología: dioses y seres mitológicos ancestrales}

La mitología de los Kañaris, nos ha revelado la existencia de deidades ancestrales, seres mitológicos y lugares sagrados propios, muchos de ellos, únicos en la cultura andina:

PACHAKAMAK, el dios creador del tiempo y el espacio; NINAMASHA, el dios del fuego; SULLAMITA, la deidad de la belleza; KUTILLA, el dios del agua; OLAY, criatura mitológica "madre del agua"; WAYRA, el dios del viento; MAMA WAKA, la guardiana de piedra; entre otros. 


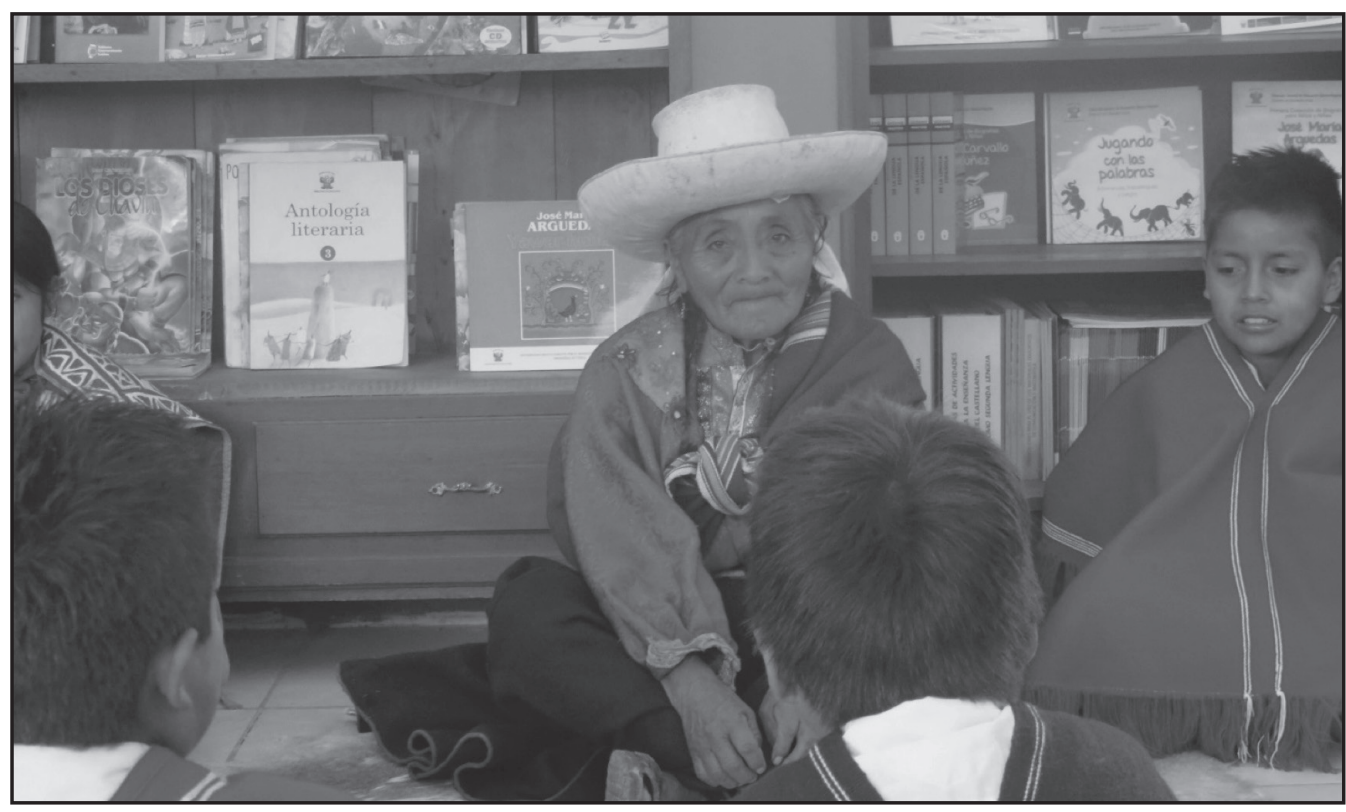

[Sabia de la comunidad narrando las tradiciones orales ancestrales de los Kańaris a los niños y niñas de la Institución Educativa N. 10244. Huamachuco, 2017].

La narración oral estuvo a cargo de las sabias ancianas, custodias de la sabiduría ancestral por antonomasia, y a partir de ello nuestros estudiantes producen textos escritos en su lengua originaria. Estas producciones han sido recopilados y sistematizados en una obra literaria titulada Dioses y seres mitológicos de Kañaris. ${ }^{2}$

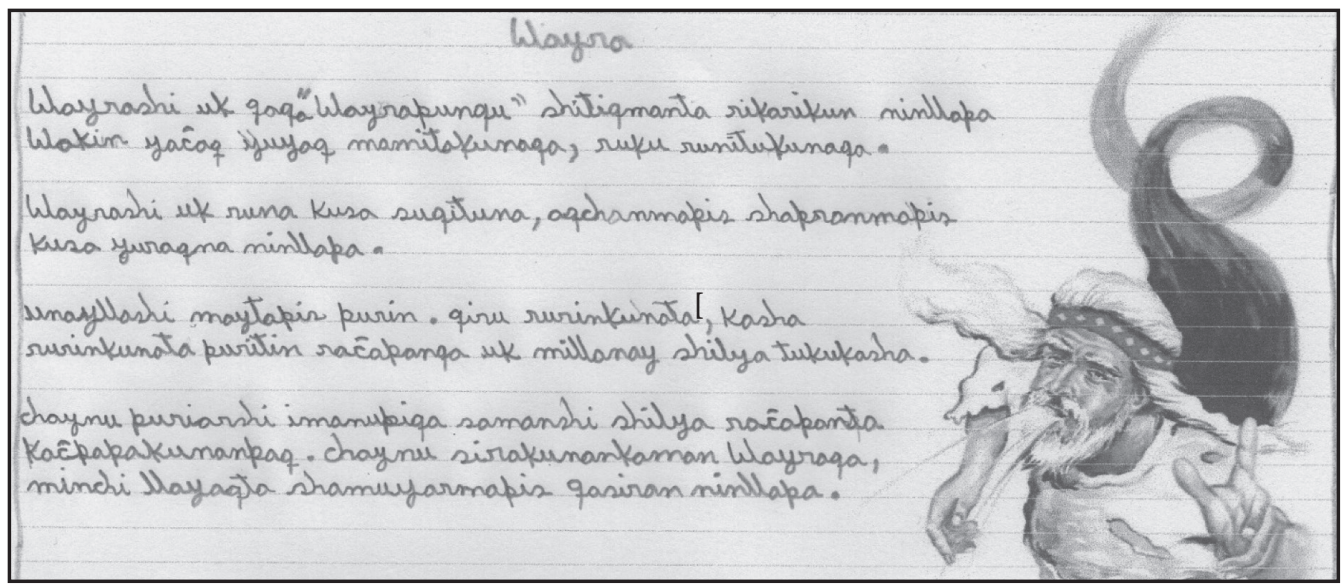

Producción literaria en lengua originaria sobre las deidades ancestrales, hecha por nuestros estudiantes de la Institución Educativa N. 10244 - Huamachuco, Kańaris].

2 Dioses y seres mitológicos de Kañaris, manuscrito en posesión del autor, con certificado de registro de obras literarias N. 006802015 INDECOPI. 


\subsection{El sistema de caminos ancestrales de Kañaris}

Los ancestros Kañaris con avanzada sabiduría y tecnología dominaron las pendientes de la Cordillera de los Andes y construyeron una extensa red de caminos que llamaron "Atun Nan”. Esta red vial ancestral formaba parte del "Qapaq Nan” del Tawantinsuyo, y servía para la integración de los pueblos originarios, para el traslado e intercambio de productos agrícolas, para el desplazamiento de los "ayllus" que se movilizaban para realizar las faenas comunales, celebración de festividades o realizar rituales. Por esta razón los trabajos de mantenimiento de este sistema de caminos es una de las actividades más importantes que se realiza anualmente en el mes de mayo en el pueblo kañari.

Para el abordaje pedagógico de esta situación de contexto, se desarrolló una secuencia de situaciones de aprendizaje con distintas actividades entre las que destacan: la preparación de una ficha de entrevista, la entrevista a los sabios ancianos de la comunidad, el reconocimiento de los elementos naturales y culturales del espacio geográfico de la comunidad, la elaboración de un mapa de los caminos ancestrales; el análisis de normas, prohibiciones y castigos que se imponían en los trabajos de mantenimiento de los caminos ancestrales, el empleo de unidades de medidas, y la elaboración de una infografía para comunicar a la población el producto de la investigación etnográfica.

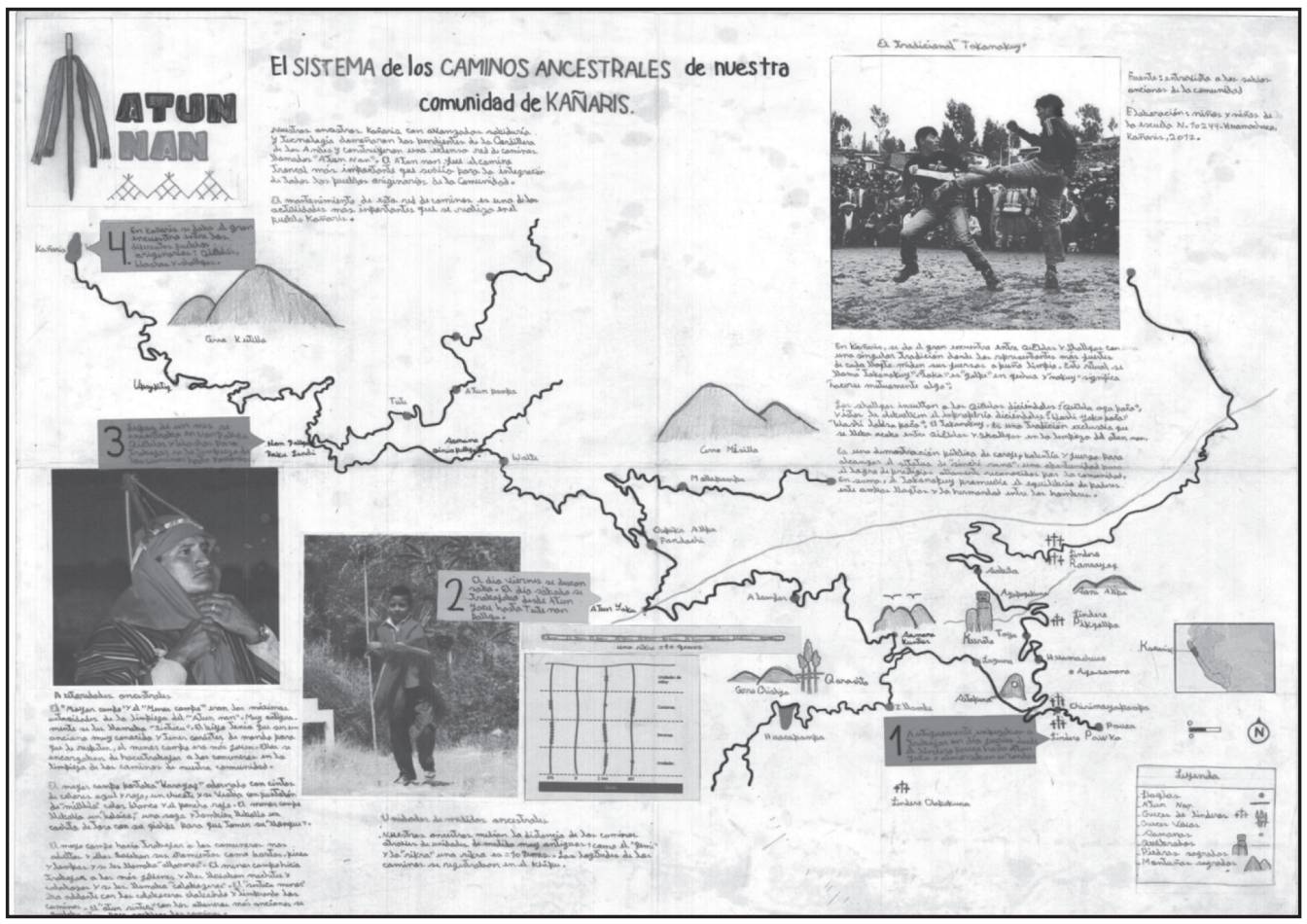

[“Atun N̂an, El sistema de caminos ancestrales de nuestra comunidad de Kańaris", infografía elaborado por estudiantes de la Institución Educativa N. 10244 - Huamachuco, Kañaris]. 
"Llaqta" o pueblos originarios. Son lugares sagrados donde nuestros primeros ancestros se establecieron hace milenios y muchos ahora son restos arqueológicos olvidados y ocultos en la montaña: "Qasay Rumi", "Densilde", "Qasay Sirka”, "Qoroĉko", "Waraq Tushuna Pampa”, "Ampatu Rumi”, "Puma Armakuna”, "Shaq Sirka", "Maray Waka", etc., estos lugares primigenios de kañaris conservan aún topónimos ancestrales y una antigua tradición oral de sus orígenes.

Cruces de linderos. Son cruces de madero de gran tamaño que nuestros abuelos ubicaron en los límites de su territorio, dos tríos de cruces a cada lado del camino ancestral, éstos servían como hitos para que los hacendados españoles no se adueñaran de sus tierras. Los trabajos de mantenimiento de los caminos ancestrales se inician en estas cruces: se tejen arcos y se adornan con flores. Las cruces de lindero que se ha identificado, son:

El lindero "Ranrayoq" (3 grandes cruces a cada lado del camino).

El lindero "Pikqollpa" (a "2000 rikras" de distancia del lindero "Ranrayoq")

El lindero "Pawka" (1 trío de cruces a cada lado del camino).

El lindero "Qarwakucho", un lugar estratégico, especie de "mirador".

Cruces vivas. Nuestros ancestros adoraban a ciertas especies de árboles nativos muy especiales, que tenían la forma de cruces. Estos árboles eran una especie de "cruces vivas", cuyas ramas y troncos caprichosamente entrelazados formaban hasta 1 docena de cruces. La gente le ofrendaba prendas de cabello de sus familiares, pelo o pluma de sus animales, tierras y frutos de sus parcelas, agua o chicha. "Qarashto", era una "cruz viva" de donde además se extraía la savia que servía de "incienso" que se quemaba en ceremonias de culto religioso. En la actualidad, quedan muy pocas "cruces vivas".

"Samana". Son instituciones ancestrales donde los pueblos Qiĉwa, Washa y Shallqa se reunían para organizarse y tomar acuerdos durante los trabajos de mantenimiento de los caminos. Estos lugares no eran edificaciones sino más bien un gran árbol, una montaña o una "pampa". Ahí se compartía comidas y bebidas con música y danzas. Era un lugar de descanso para los viajeros que transitaban a la costa; incluso los muertos tienen sus propias "samanas".

"Ñan Pallqa", es la "samana" más emblemáticas de nuestro pueblo Kañari. Se trata de un viejo árbol milenario llamado "Raku Lanchi", que se encuentra en el camino ancestral "Atun Nan". "Ñan Pallqa" significa "punto de unión de varios caminos", en este lugar nuestros ancestros Qichwa y Washa se "encontraban", se "unían" para realizar grandes jornadas de trabajo de mantenimiento del sistema de caminos del "Qhapaq Nan". Entre otras podemos citar a "Upay Peteq", "Samana Parayoq", "Samana Kuntur", "Samanapampa" y "Ayasamana". 
Litomorfosis. Son piedras ciclópeas o figuras megalíticas. No se trata de cualquier elemento natural, son los entes tutelares, lugares muy sagrados para nuestros ancestros. Por ejemplo, el complejo litomórfico de "Maray Waka": en la entrada del camino custodian dos enormes rocas que tienen forma de rostro humano, una gran roca esférica sobrepuesta en otra de gran altura, evoca a un "hombre gigante en posición vertical”. En la base de estas gigantescas rocas se ha tallado portales triangulares y arqueados, que constituyeron espacios muy sagrados para realizar actos rituales. Dentro de uno de ellos se halla un hermoso marcador astronómico o ritual. Incluso muy cerca de este enigmático espacio circundante hay restos del recinto del sacerdote astrónomo.

Entre otras rocas sagradas está el "Kurato": es una pareja de rocas verticales de formas humanoides [se dice que son: hombre y mujer]. "Sitakuna Rumi", una roca vertical que tiene un pequeño orificio donde los caminantes lanzan piedrecitas para "consultar su suerte".

Montañas sagradas. "Kutilla", "Misilla”, "Suni Waka", "Sani Allpa" "Kuntur", "Chishya", "Wamana Qaqa" son algunas montańas sagradas de nuestro pueblo Kañari. "Atunyaku” y "Kañaryaku" son las quebradas más importantes.

Autoridades ancestrales. El "Mayor Campo" y el "Menor Campo" eran las autoridades máximas de las faenas de mantenimiento de los caminos ancestrales de la nación de los Kañaris. Sin embargo, hace mucho tiempo se les llamaba "Sintiku". El "Mayor Campo" era un anciano y el "Menor Campo" era el más joven. Ellos se encargaban de organizar a los comuneros para las faenas de mantenimiento de los caminos de nuestra comunidad.

El "Mayor Campo" era elegido por la comunidad en una asamblea y el "Menor Campo" era elegido por el "Mayor Campo" en la primera faena del "atavío de las cruces de lindero de la comunidad". El "Mayor Campo" no podía ser cualquier persona, tenía que ser una persona "fuerte" y tener carácter "de mando" para que lo respeten.

El "Viejo Campo" portaba un pequeño "cetro de mando" adornado con cintas de color rojo y azul; llevaba un chicote y se vestía con pocho rojo y un pantalón blanco de lana de oveja. En su cabeza llevaba un sombrero ancestral cónico llamado "Wamachuku". El "Menor Campo" llevaba en su alforja una soga y también una copa de "cuerno de toro" y un "qishpi" para que tomen su chicha o aguardiente.

El "Menor Campo" hacia trabajar a los comuneros más jóvenes -que se llamaban entrantes- ellos iban en la delantera, con calabozos y machetes "chaleando" los montes de los caminos, por eso se les llama también "calaboceros". En cambio, el "Viejo Campo" hacia trabajar a los comuneros más adultos y ancianos con barretas, picos y lampas, y se hacían llamar "allaneros". El "Mayor Campo" con los "allaneros" iban ampliando los caminos, construyendo escaleras de piedras, o reparando los puentes de palos y sogas. 
Código de normas y castigos. En las faenas de mantenimiento de los caminos se asumían un código de normas y prohibiciones que regulaba las conductas de hombres y mujeres de la comunidad. En estos encuentros se imponían severos castigos a quienes estaban en falta. De esta manera se garantizaba el buen vivir de las personas con sus semejantes, con la naturaleza y con los seres espirituales que habitan en ella.

Los pobladores tenían la costumbre de llevar flores, hilos de algodón y carrizo para el "atavío de las cruces de lindero de la comunidad". Las viudas o madres solteras, que ya no tenían un esposo o hijo mayor que las representen colaboraban con hilos de algodón, flores o chicha para estas actividades. En casa, las esposas debían de amarrar flores a las pequeńas cruces que tenían colgados a cada lado de la puerta de sus casas y mantener limpio la vereda de sus domicilios.

En la hora del almuerzo eran obligados sacarse los gorros, y parar las herramientas de trabajo "fierro arriba". Siempre se compartía los alimentos entre todos haciendo una gran rueda, estaba prohibido comer aislado del grupo.

En estos trabajos no se podía golpear el calabozo en las piedras, ni hablar palabras soeces. Cuando en la faena los comuneros hacían chocar sus calabozos en la piedra o entre herramientas, o cuando en la hora del almuerzo no se quitaban sus gorros o paraban sus herramientas "fierro abajo" le hacían gastar un "cuarto" de aguardiente, pero si hablaban palabras soeces, o desobedecían a la autoridad eran castigados con chicote.

Si algún poblador no cercaba su chacra o no deshierbaba sus cultivos de maíz, el "Mayor Campo" lo castigaba por haragán, lo amarraban con soga y le panqueaban con chicote.

Los pobladores que eran borrachos, descuidaban a sus hijos que andaban sucios y se maltrataban de hambre, o golpeaban a sus mujeres, eran públicamente castigados en asamblea; lo amarraban con soga, le penqueaban con chicote y le metían a una cárcel donde hacía mucho frío y había chinches y garrapatas. Así mismo los hombres que no cuidaban de sus padres ancianos, hermanos u otros familiares huérfanos, minusválidos o enfermos eran duramente castigados.

\section{El “Takanakuy” entre Qiĉwas y Shallqas}

Para el mantenimiento del sistema de caminos ancestrales: ["chaleo", ampliación de caminos, instalación de escaleras, construcción de puentes] se realizaban grandes faenas comunales que movilizaban a los pueblos Qiĉwa, Washa y Shallqa de la nación Kañari.

Los "washa runas" se encuentran con los "qiĉwa runas" en "Ñan Pallqa", desde ahí iban juntos trabajando rumbo a Kañaris. Llegando a Kañaris, desde "Wamana qaqa" los "shallqa runas" que estaban faenando al otro lado de la ladera incitaban a los "qiĉwa runas" diciéndoles: "Qiĉwa aqas paçakuna" y estos le devolvían el improperio diciéndoles: "Washi yaku paĉa", "washi lawsa paĉa". Continuaban las incitaciones de bando a bando hasta coincidir en Kañaris. 
En Kañaris, se da el gran encuentro y vaya que con una singular tradición donde los representantes más fuertes de cada pueblo miden sus fuerzas a puño limpio. Este ritual se llama "takanakuy", que significa "golpearse mutuamente algo".

"En medio de un rodeo que se forma, un representante de los shallqas Eleodoro Qishpi, no puede esperar más y elige con el dedo a su adversario entre la multitud. El elegido es Rosendo Waman, un qiĉwa a quien le dicen "rumi maki", no tiene miedo y da un paso adelante. Ambos se la tenían jurados desde hace algún tiempo, para saber quién era el más fuerte ya que el vencedor ganará respeto entre todos los hombres de la comunidad.

Sin calentamientos ni previo aviso empiezan los ataques de puños, codos, cabezazos y patadas van y vienen, algunos se esquivan, pero dos severos puñetazos en la cara hacen caer al suelo a Eleodoro Qishpi.

No importa si el desafío se realiza bajo un ardiente sol o en lluvia. Solo cuando ambos contrincantes se sienten agotados detienen la pelea. Al final ambos se abrazan, y sin rencores comparten la chicha o el aguardiente" [Testimonio de Justiniano Mendoza Reyes (90 años). Huacapampa, Kañaris].

Esta tradición tiene su origen en la cultura Chanka y se realiza especialmente en los poblados del Cuzco y Apurímac. Para el antropólogo Harold Hernández, quién ha escrito el mejor ensayo sobre el "takanakuy", existen tres razones para estas violentas celebraciones: por conflictos vinculados a posesión de tierra o abigeato, por 'deporte' y para decidir situaciones sentimentales.

"Es un encuentro peculiar en el que se intercambian golpes legítimos y aceptados por la sociedad, pues deciden, sancionan, resuelven conflictos y reconocen poder. "Es un intento de expulsar, con la violencia 'buena’, la 'mala' violencia” (Hernández, 2013).

Sin embargo, para los Kañaris, el "takanakuy", es una tradición exclusiva que se lleva a cabo entre "Qiĉwas" y "Shallqas" al término de las faenas de mantenimiento de los caminos ancestrales de la comunidad. Se cree que este acontecimiento es uno de los más esperados, puesto que es una oportunidad de demostración pública de coraje, valentía y fortaleza física para alcanzar el status de "Shinchi", una oportunidad para el logro de prestigio altamente reconocido por la comunidad.

La etnografía nos ha dado interesantes aportes respecto a su origen: "Cuentan que hace mucho tiempo venían de Cajamarca 200 "chankas" hacia Kañaris con fines de someterlos bajo guerra. Enterados de tal propósito 100 valientes guerreros Kañaris van hacia su encuentro. Dicen que, aunque nuestros guerreros estaban en desventaja en número salieron triunfantes del encuentro con los "chankas", y de ese modo se impidió que llegarán a nuestro pueblo. Desde ese entonces se hace el "takanakuy" en nuestro pueblo.” [Testimonio de Isidro Roque Manay (70 años). Illambe, Kañaris.]

Se trata de un ritual en memoria del triunfo de nuestro pueblo sobre los aguerridos "chancas", una memoria colectiva transmitida de generación en generación. El "takanakuy" promueve la hermandad entre los runas y el equilibro de poderes entre los pueblos "Qiĉwa" y "Shallqa" de Kañaris. 


\section{Reconstruyendo las matemáticas ancestrales}

Se ha incorporado en la práctica pedagógica los conocimientos matemáticos de nuestro pueblo originario como son algunas unidades de medidas de longitud, masa, sistema de conteo, y el empleo de instrumentos y estrategias de cálculo aritmético y registro numérico ancestrales; $y$ a partir de esta experiencia se propone una secuencia metodológica para el abordaje y el tratamiento curricular de la etnomatemática de un pueblo étnico cultural.

\section{1. Unidades e instrumentos de medidas ancestrales}

"La rikra", es una unidad antropométrica que empleaban para medir longitudes y distancias de los caminos ancestrales. "1 rikra", es longitud que separa las puntas de los dos dedos pulgares de un hombre con los brazos extendidos, habiendo hecho los kañaris el uso de la antropometría tal como muchos pueblos de la antigüedad (Kula, 1999). "1 rikra" equivale a "10 qemes". El "qeme", longitud existente entre el dedo índice y el pulgar, separando uno del otro lo máximo posible.

Algunas unidades de medidas que empleaban para medir la "masa" de las cosechas de maíz, fréjol, papa, oca y productos agrícolas: "1 qaptay" < "1 mati" < "1 meqllay" < "1 shipu" < "1 kinrampa" < "1ashtay".

Sistema de conteo ancestral empleado por las tejedoras: (a) para la medida de la lana y/o algodón: "pillun" y el "wanku"; (b) para contabilizar las cantidades de hilos:

$$
\begin{aligned}
& 2 \text { "shukshu" :: } 1 \text { "runa" } \\
& 4 \text { "shukshu" :: } 2 \text { "runa" } \\
& 6 \text { "shukshu" :: } 3 \text { "runa" }
\end{aligned}
$$

Se trata de un sistema de conteo ancestral llamado "runa": numeración binaria que hace milenios conocían los kañaris.

\subsection{Propuesta didáctica para el abordaje y tratamiento curricular de los cono- cimientos matemáticos de un pueblo originario}

A diferencia de la matemática convencional, que parte de operaciones básicas de reconocer los números, sumar y restar; la etnomatemática, se inicia con el reconocimiento y la valoración del entorno natural, social y cultural de una comunidad ( D’Ambrosio, 2014), ya que, con este conocimiento aplicado a la vida cotidiana, podremos cuidar la Madre Tierra y todo cuanto vive en ella.

En este proceso de construcción de una propuesta didáctica se propone una secuencia metodológica para el abordaje y tratamiento curricular de los conocimientos matemáticos de un pueblo originario: (1) La vivenciación cultural; (2) La sistematización del conocimiento etnomatemático; (3) La resolución de un problema matemático de la situación sociocultural; (4) El empleo de estrategias e instrumentos ancestrales; (5) La comunicación y representación del proceso de resolución; y, (6) La reflexión.

En esta oportunidad explicitaré esta propuesta metodológica, mediante el ejemplo de algunas situaciones de aprendizaje desarrollado con los niños y las niñas sobre algunas unidades de medidas ancestrales propias de los Kańaris. 


\section{1) La vivenciación cultural}

Implica la participación directa en una actividad agrícola, ganadera, ritual o festiva de la comunidad, respetando el tiempo y el espacio en la que ésta se desarrolla.

Por ejemplo, en el contexto de las faenas de mantenimiento del sistema de caminos que realizan los pobladores de Kańaris, emplean algunas unidades e instrumentos de medidas de longitud. Nuestros estudiantes visitaron a los pobladores cuando hacían estos trabajos y un sabio anciano les enseńó a medir la longitud de los caminos empleando un instrumento ancestral llamado "rikra". Los estudiantes aprendieron a medir la longitud del camino de su comunidad siempre verbalizando la medida en su lengua originaria:

"Uk rikra, ishkay rikra, kimsa rikra, tawa rikra, pichqa rikra, suqta rikra, kanchis rikra, pusaq rikra, isqun rikra, uk chunka rikra, uk chunka ishkay rikra, uk chunka kimsa rikra, uk chunka tawa rikra,......, uk chunka isqun rikra, ishkay chunka rikra" como mínimo se propuso medir hasta "20 rikras".

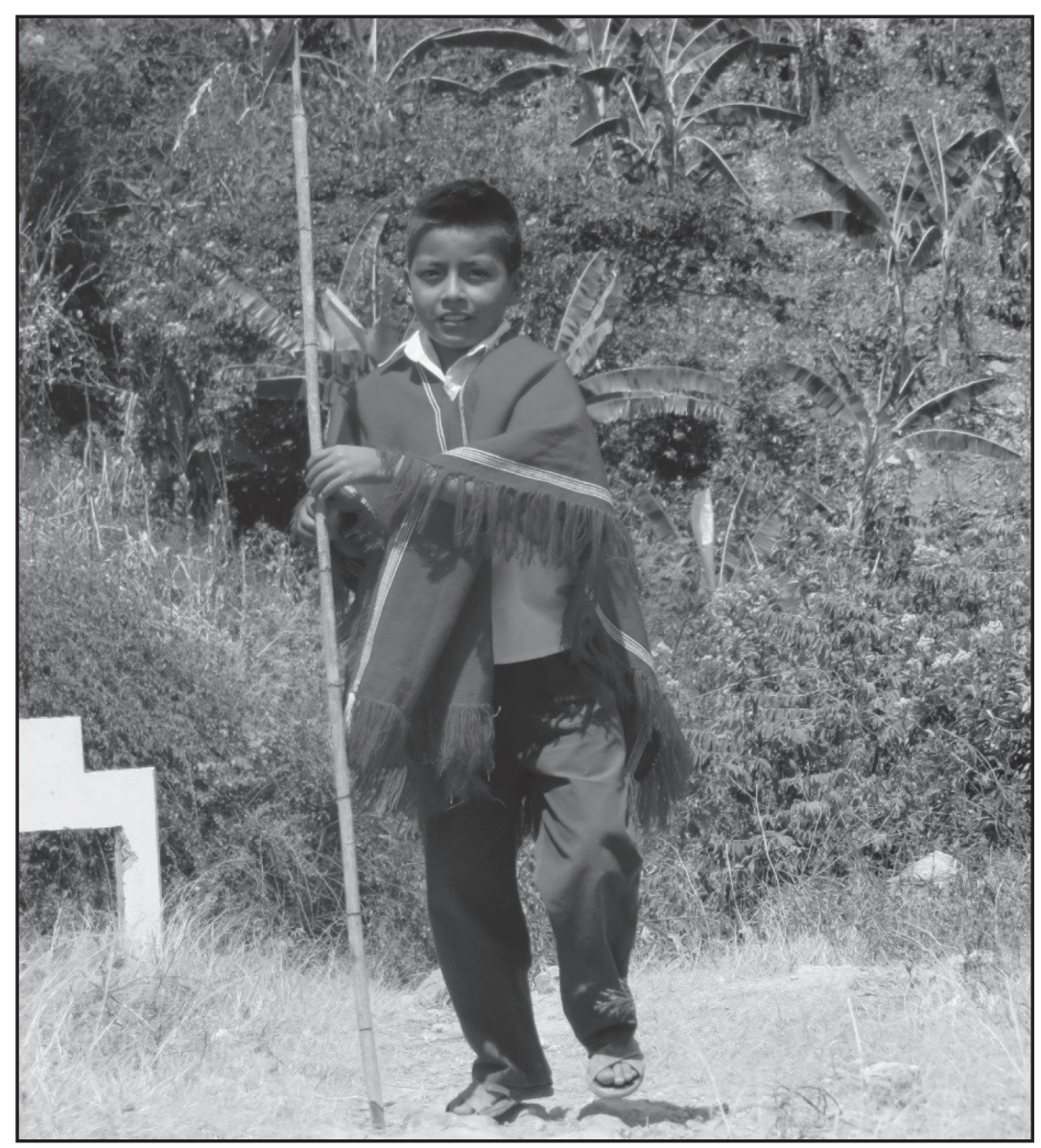

[Nińo del 4to grado de la Institución Educativa N. 10244, participando en la medición de la longitud de los caminos. Huamachuco, 2017]. 
En otro contexto sociocultural, nuestros estudiantes participaron de la cosecha del maíz en la chacra de una sabia de la comunidad. Ella les mostró algunas unidades de medidas de masa. Los estudiantes emplearon las unidades de medidas mostradas por la sabia de la comunidad siempre verbalizando la medida en su lengua originaria.

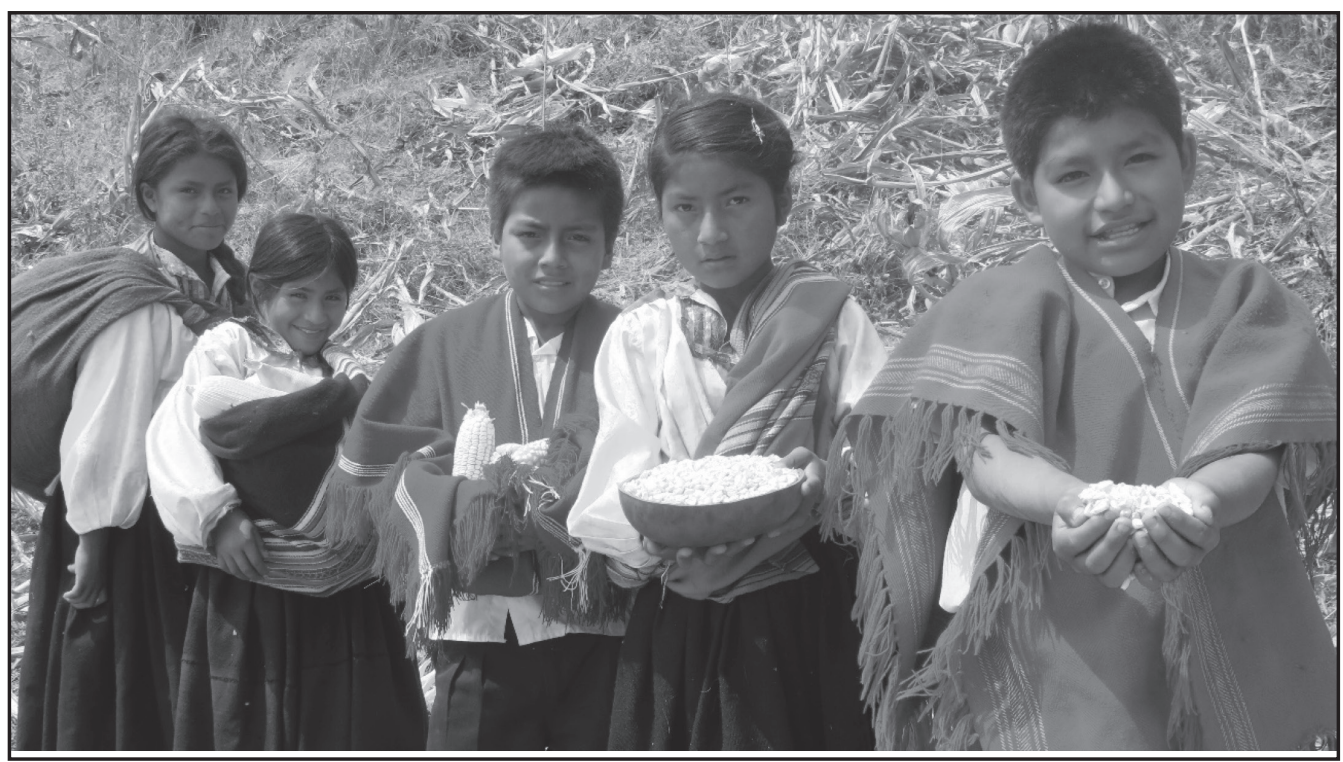

[Niños y niñas de Institución Educativa N. 10244 reconociendo las unidades de medidas de su comunidad empleados para intercambiar productos agrícolas: "qaptay" > "mati" > "meqllay" > "shipu" > "kinrampa" < "ashtay". (Huamachuco, 2017)].

\section{2) La sistematización del conocimiento etnomatemático}

En esta etapa se reconstruyen los conocimientos matemáticos, se redescubren algunos patrones, equivalencias o regularidades, respetando siempre la lógica de los saberes locales.

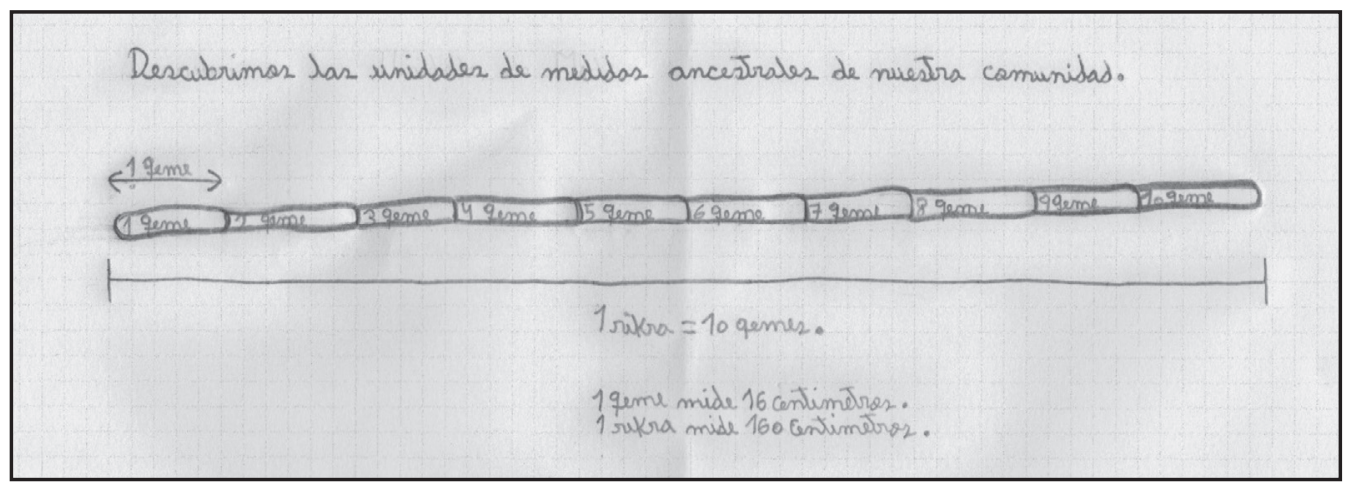

[Sistematización de las unidades de medidas ancestrales de longitud propias de la comunidad. Tomado del cuaderno de trabajo de uno de los estudiantes de la II.EE N.10244 Huamachuco, Kańaris]. 


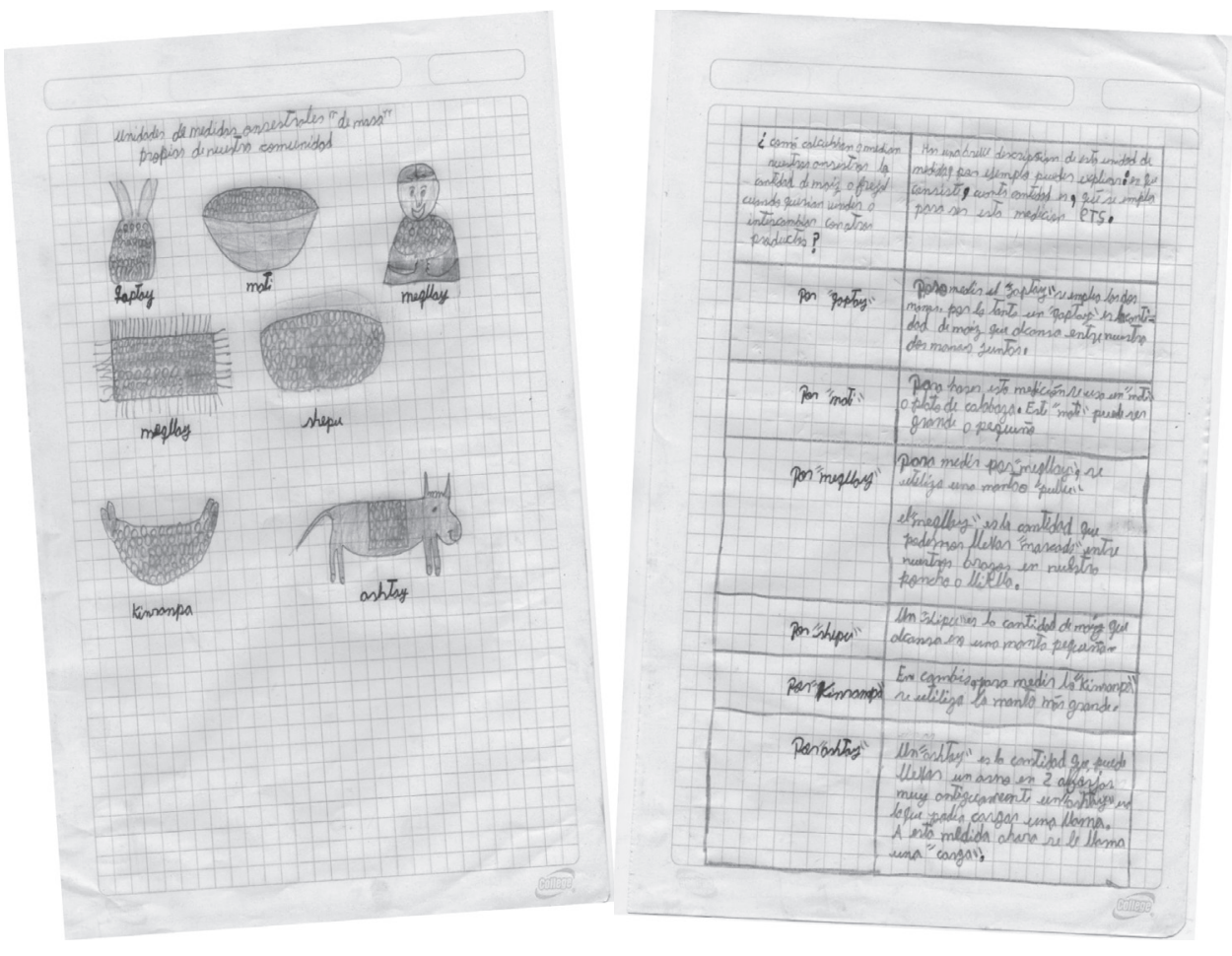

[Descripción de las unidades de medidas ancestrales de masa. Tomado del cuaderno de trabajo de uno de los estudiantes de la II.EE N.10244 Huamachuco, Kańaris].

\section{3) Planteamiento y resolución de un problema matemático}

En esta etapa se plantea un problema matemático de la situación sociocultural con el objetivo de promover el desarrollo de competencias y capacidades matemáticas. ${ }^{3}$ Para resolver la situación problemática los estudiantes transitan por un conjunto de fases de resolución de problemas. ${ }^{4}$

En esta propuesta se asume el enfoque pedagógico de resolución de problemas como eje vertebrador alrededor del cual se organiza la construcción, enseñanza, aprendizaje y evaluación de los conocimientos matemáticos. Un aprendizaje enfocado en la construcción de conocimientos matemáticos a partir de la resolución de situaciones problemáticas, apunta al desarrollo de determinadas competencias y capacidades matemáticas (Ministerio de Educación, 2015).

3 Las cuatro capacidades matemáticas que establece el Currículo Nacional de Perú son: (1) matematiza situaciones, (2) comunica y representa ideas matemáticas, (3) elabora y usa estrategias y (4) razona y argumenta generando ideas matemáticas.

4 De acuerdo a George Pólya (1945) resolver un problema, comprende transitar por un conjunto de fases, que se complementan entre sí, es decir un proceso recurrente de idas y vueltas entre (1) la familiarización y comprensión del problema, (2) la búsqueda de estrategia y elaboración de un plan, (3) la ejecución del plan y control, y (4) la visión retrospectiva y prospectiva sobre el proceso de resolución. 
Por ejemplo, nuestros estudiantes redactaron distintas situaciones problemáticas sobre la cantidad de maíz y frejol que cosecharon por cada chacra.

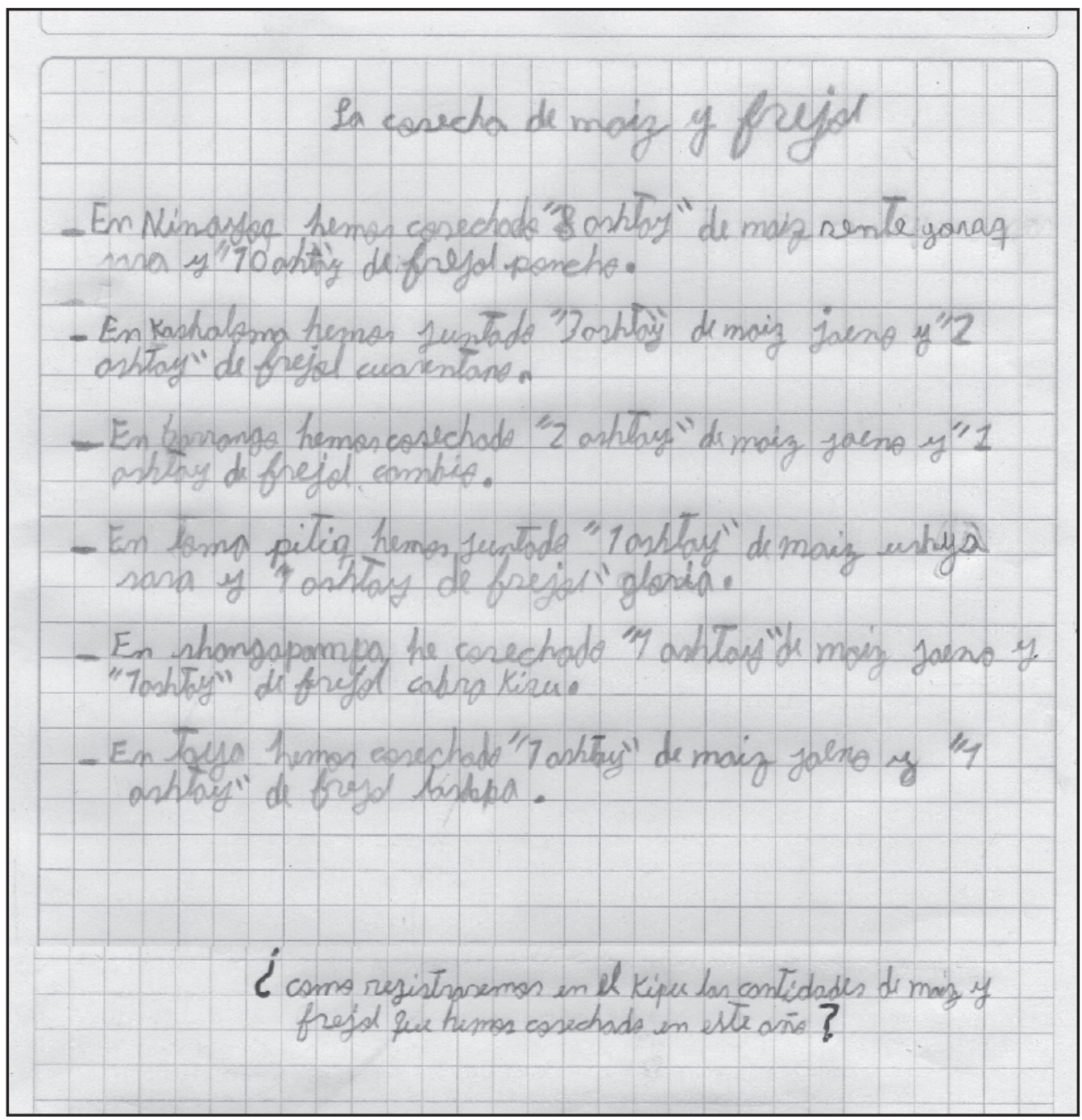

[Redacción de un problema matemático sobre la cosecha anual de maíz y frejol de la comunidad. Tomado del cuaderno de trabajo de uno de los estudiantes de la II.EE N.10244 Huamachuco, Kañaris].

4) Empleo de estrategias e instrumentos ancestrales de cálculo aritmético y registro numérico: El empleo de la "yupana inka" y la confección de "khipus"

Empleando semillas de maíz y frejol sobre el telar de la "yupana inka”, encontraron la respuesta al problema sin necesidad de ejecutar el cálculo matemático convencional. El

5 La “yupana inka”, es el instrumento ancestral de la cultura andina que sirve para contar. 
método empleado fue el "Tawa Pukllay” ("Los 4 Juegos Sagrados de los Inkas") la única matemática que se desenvuelve a manera de juegos y no requiere cálculos numéricos mentales. En este método permite realizar sumas sin sumar, restas sin restar, multiplicaciones sin recurrir a memorizar tablas de factores, realizar grandes divisiones con la cantidad de decimales que quiera encontrar y sin hacer cálculos matemáticos (Prem, 2016).

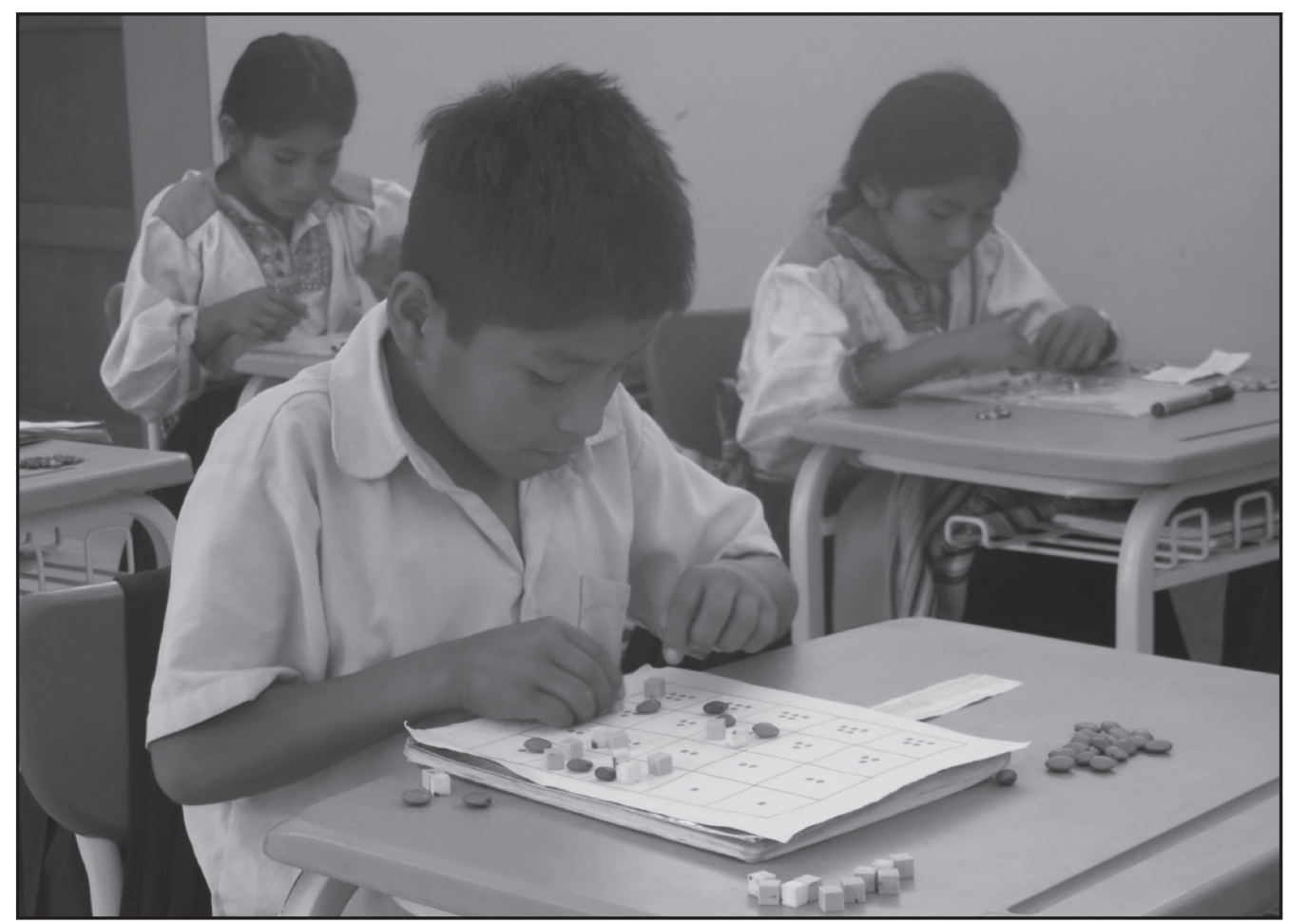

[Niños y niñas de la Institución Educativa N. 10244, empleando la “yupana inka” para hallar la respuesta a la situación problemática planteada (Huamachuco, 2017)].

Luego, los estudiantes aprendieron a confeccionar "khipus numéricos" ${ }^{6}$ para almacenar información cuantitativa sobre situaciones cotidianas de su comunidad: "sara pallay", "puspu urquy", "akshu allay" (cosecha del maíz, frejoles y papa, respectivamente). Emplearon hilos de algodón de variados colores, aprendieron a hacer nudos simples y compuestos, con tal propósito se creó un instrumento llamado "khipokoq" que inicialmente facilitó hacer nudos compuestos. De este modo nuestros estudiantes desarrollan la competencia de gestión de datos, que implica la recopilación y el procesamiento de datos, su interpretación y valoración.

6 El "khipu numérico" es aquel en el que cada una de las cuerdas se puede identificar espacios diferenciados entre cada grupo de nudos que representan las unidades, decenas, centenas y unidades de millar respectivamente. 


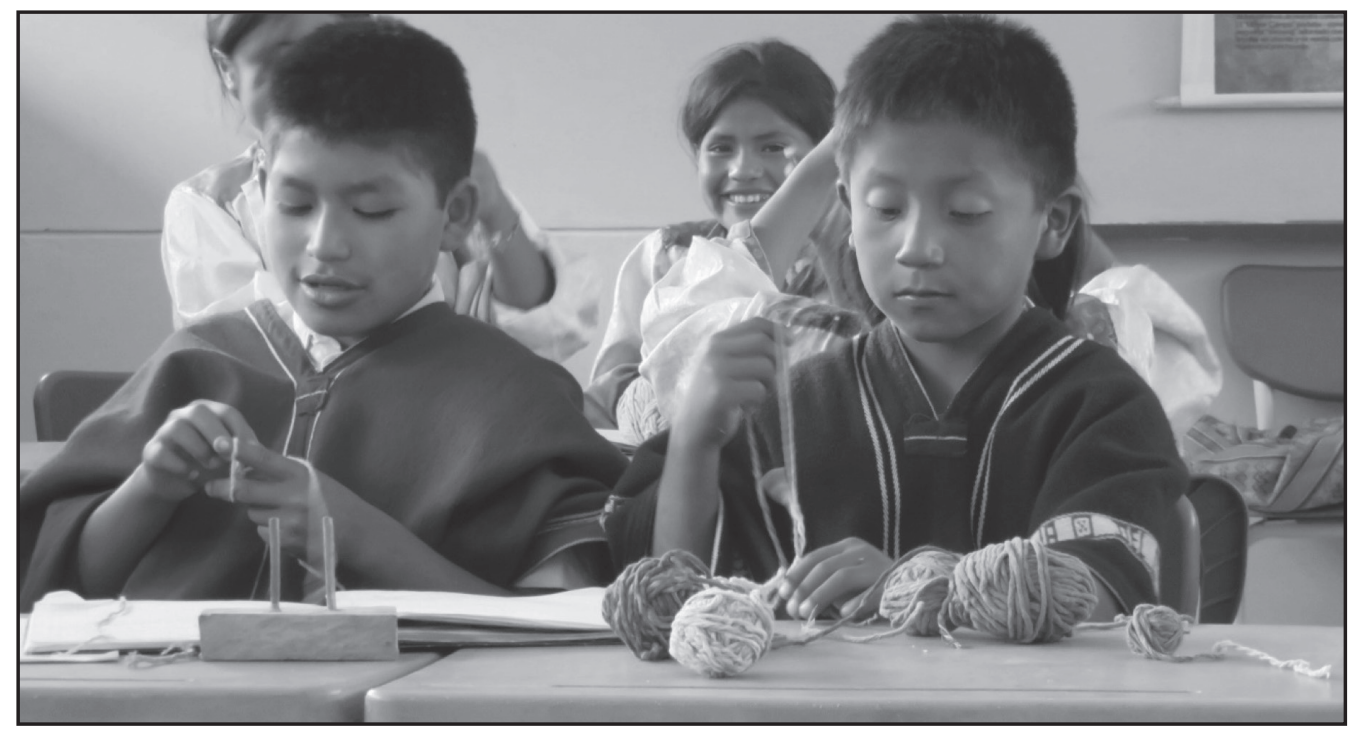

[Estudiantes en proceso de elaboración de “khipus numéricos” (Huamachuco, 2017)].

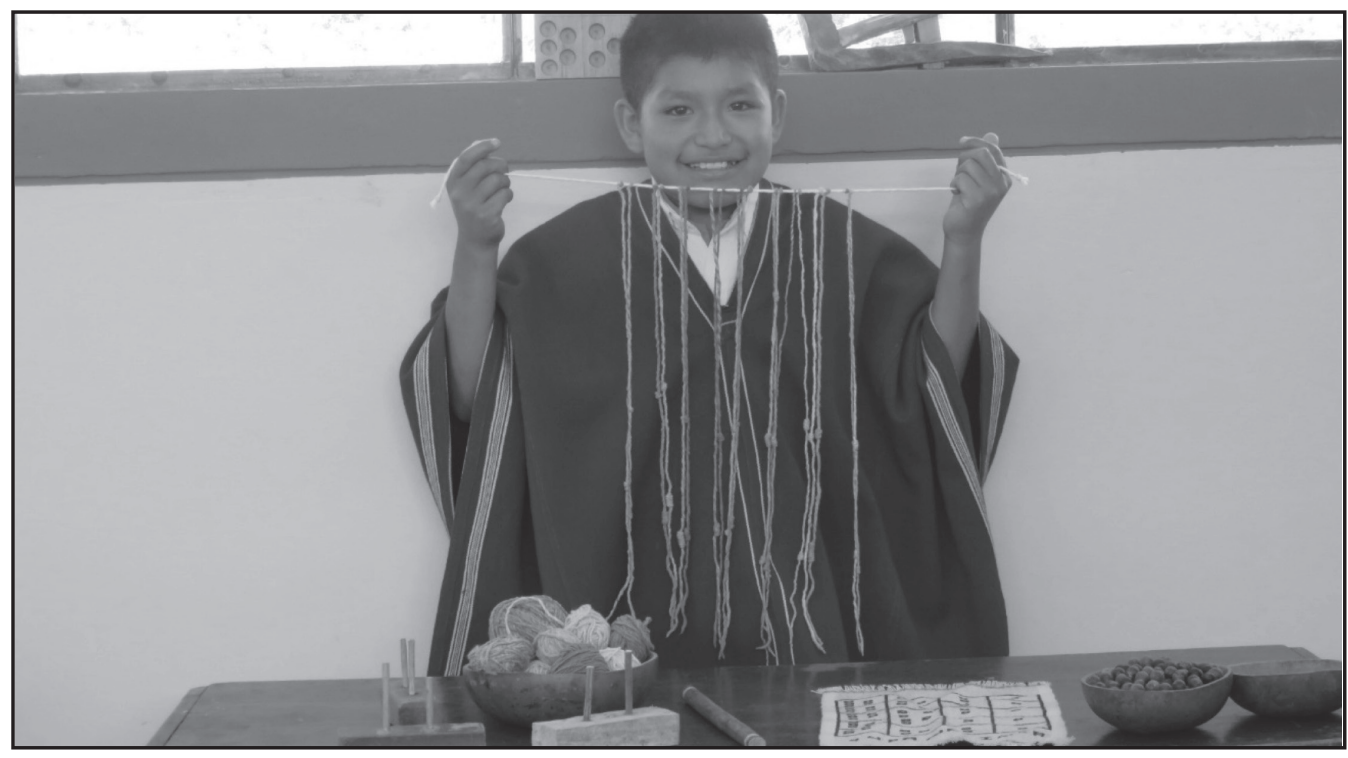

[Wilbert (10 años) el nuevo "Khipukamayoq" mostrando el "khipu numérico” que han confeccionado para almacenar los resultados de sus operaciones en la "yupana inka" (Huamachuco, 2017)].

\section{5) Representación ${ }^{7}$ y comunicación del proceso de resolución}

En esta etapa nuestros estudiantes expresan el proceso de resolución de forma

7 La representación es un proceso y un producto que implica seleccionar, interpretar, traducir y usar una variedad de esquemas para expresar una situación, interactuar con el problema o presentar un resultado. 
oral y escrita usando el lenguaje matemático y diversas formas de representación desde las vivenciales hasta llegar a las representaciones gráficas y simbólicas.

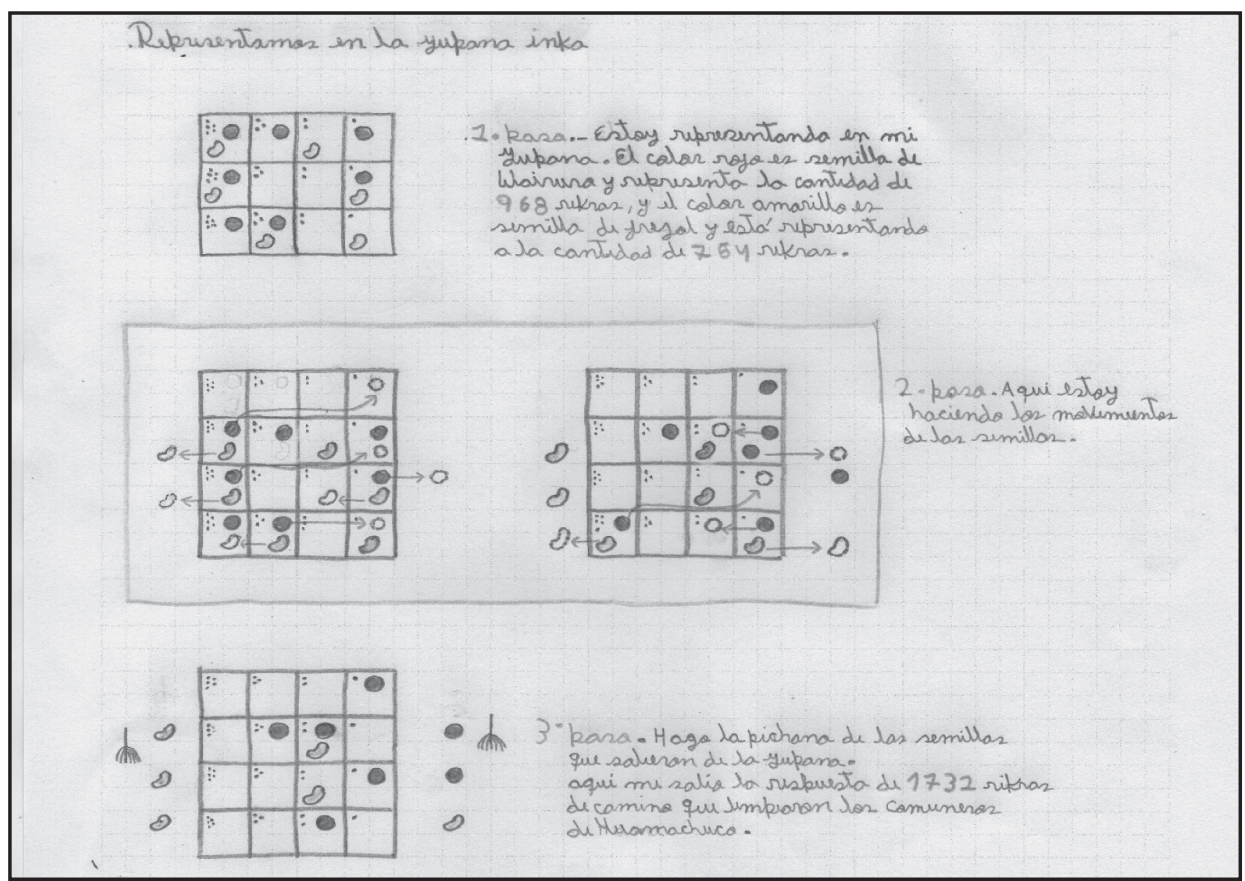

[Representación gráfica y simbólica del proceso de resolución del problema empleando la “yupana inka” (Huamachuco, 2017)].

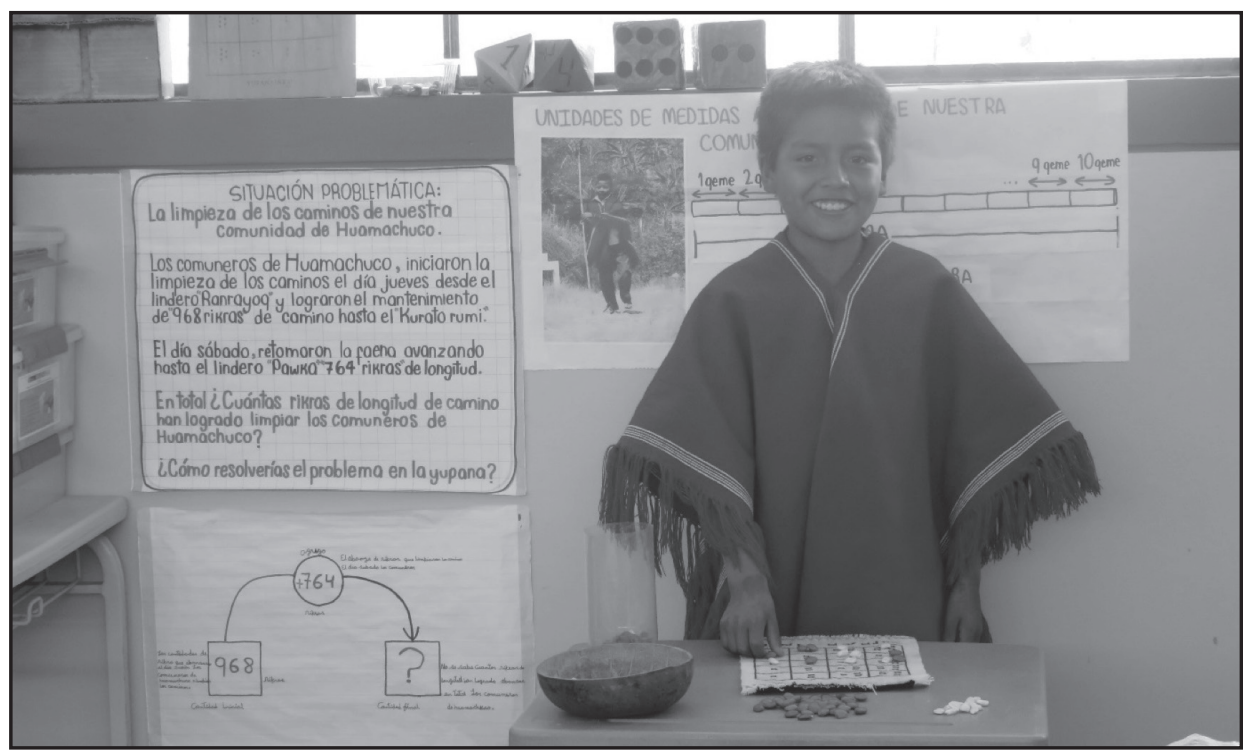

[Junior (10 años), argumentando las estrategias y los recursos que empleó para solucionar la situación problemática planteada sobre la longitud de los caminos ancestrales (Huamachuco, 2017)]. 


\section{6) Reflexión del proceso de resolución}

Este momento es muy importante, pues permite a los estudiantes reflexionar sobre el trabajo realizado. En esta etapa se busca que el estudiante recuerde y reflexione sobre los procesos vivenciados y evalúe los resultados obtenidos; explique y argumente sus aciertos y desaciertos; sus preferencias para aprender y las emociones experimentadas durante el proceso de solución.

Esta reflexión puede realizarse puede ser forma oral o por escrito y de forma individual respondiendo algunas preguntas de metacognición.

1. ¿Cómo hiciste para hallar la respuesta? Explica tu estrategia paso a paso.

- Ha primina entendi bien el prablema de que se trataba

- y lugga hice una estralegia del modela grofica pana resdeler el perselema muy bien

- pera luega na salia la respuesta yla hice en la Yupana hacienda

lar mollimientar y luga me ralia la respuesta

- y Juege do sume para ber si salia bien la respuesta

2. ¿Qué te dio la pista para elegir tu estrategia? ¿En qué se parece este problema a otros trabajados anteriormente?

- A mi mi dia pista que el probalema se trataka para juntar las mididar de lo que trateajaron los comuniras

- este probalema se parese al que ya hemas Trabajada sobare las

prapitarion que tambien era para Juntar cantidades

3. ¿Te fue fácil o difícil resolver el problema? ¿por qué?, ¿tuviste alguna dificultad? ¿cómo superaste esa dificultad?

- A mi me fue facil resolvar ese prablema era parecido al que ya hemas resuelta

- y Tambien porque era facil sacar la respuesta en la yupana kanque se hacia las mokimientos y la pechana y se sacaba facil el resultada

4. ¿Qué aprendiste con esta actividad?, ¿qué crees que te falta por aprender bien?, ¿qué debes hacer para aprenderlo?

- Yo aprindi que camo antes media la langitut de lor cominos el senciku

- a mi me falta aprender a representos las resultadas de la yupana en mi cuaderna.

- La me compromito a practicar toda las dias en la yupana para lagrarla lo que me fatta aprender

[Ficha de metacognición sobre el proceso de resolución de la situación problemática planteada sobre la longitud de los caminos ancestrales (Huamachuco, 2017)]. 


\section{Conclusiones, resultados y discusiones}

Esta experiencia pedagógica, está posibilitando el rescate y la incorporación de la lengua originaria y los saberes ancestrales de los Kañaris en la práctica docente EIB, lo que contribuye a la mejora del desempeńo docente. Pero, sobre todo esta experiencia, ha permitido mejorar significativamente los aprendizajes de los niños y nińas, quienes están desarrollando competencias y alcanzando los estándares de aprendizajes nacionales que propone nuestro Currículo Nacional.

Después de 500 años, o tal vez más, nuestra comunidad se esfuerza ahora por recuperar y enseñar sus matemáticas ancestrales: sistemas de conteo antiguos, unidades de medidas locales, el uso de la "yupana inka" y el registro en "khipus" para hacerlos prácticos en la vida diaria en la comunidad y la escuela.

Se ha incorporado algunos conocimientos matemáticos y formas propias de aprender de los pueblos originarios como mecanismo de favorecer a la revitalización cultural. En base a esta enseñanza situada se propone una secuencia metodológica para el abordaje y el tratamiento curricular de los conocimientos matemáticos de un pueblo originario:

(1) La vivenciación cultural; (2) La sistematización del conocimiento etnomatemático; (3) La resolución de un problema matemático de la situación sociocultural; (4) El empleo de estrategias e instrumentos ancestrales; (5) La comunicación y representación del proceso de resolución y (6) La reflexión.

Esta propuesta pedagógica se enmarca dentro del Programa Etnomatemática ( D’Ambrosio, 2014), y dentro de los lineamientos generales del Ministerio de Educación de Perú, con una secuencia metodológica situada y contextualizada en el ámbito de una comunidad autóctona, donde el aprendizaje escolar también se realiza fuera del aula de clase, en la misma comunidad; el idioma originario "El quechua de los Kañaris" está presente en todas las actividades propuestas y la filosofía se circunscribe dentro de la cosmovisión andina.

En Kañaris, se está construyendo una Propuesta Pedagógica de Educación Intercultural Bilingüe (EIB) en conjunto con las comunidades indígenas, con el apoyo de los sabios y sabias de la comunidad, y con el apoyo de los docentes bilingües que están implementando este tipo de prácticas pedagógicas a nivel de Red Educativa en las escuelas rurales aledañas a la institución educativa donde se desarrolla esta experiencia pedagógica.

\section{Referencias}

D’Ambrosio, U. (2014). Las bases conceptuales del programa etnomatemática. Revista Latinoamericana de Etnomatemática, 7(2), 100-107.

Fernández, J.C. (2010). Cañaris del norte, cañaris del sur: una visión desde el norte del Perú. Revista Perspectivas Latinoamericanas (7), 58-73 
Hernández, Harold. (2013). Takanakuy: Los límites de la cultura y lo jurídico. Mesa redonda. Revista de Investigación de la Universidad Norbert Wiener, 2014, N.3

Kula, W. (1999). Las medidas y los hombres. Madrid: Siglo XXI.

Martínez, M. (1998). La investigación cualitativa etnográfica en educación: manual teórico-práctico. México: Trillas.

Ministerio de Educación. (2015). ¿Qué y cómo aprenden nuestros niños y niñas? Ruta de aprendizaje del área curricular matemática. Lima-Perú.

Ministerio de Educación. (2016). El programa curricular del nivel de Educación Primaria. Lima-Perú.

Pólya, G. (1965). Cómo plantear y resolver problemas. México: Trillas.

Prem, D. (2016). Yupana Inka: Método Tawa Pukllay. Decodificando la matemática Inka. Lima: Universidad de Lima.

Torero Fernández de Córdova, Alfredo A. (1964). Los dialéctos quechuas. Anales Cientificos de la Universidad Agraria (La Molina (Lima)) 2 (4): 446-478. 